\title{
The digital in the nursery and kindergarten: create immersive narratives through collaboration
}

\author{
Valentina Pennazio ${ }^{\mathrm{a}}$, Andrea Traverso ${ }^{\mathrm{b} 1}$ \\ ${ }^{a}$ University of Genova, Italy,valentina.pennazio@unige.it \\ ${ }^{b}$ University of Genova, Italy, a.traverso@unige.it, 0000-0003-4983-7226
}

\begin{abstract}
This paper presents a research experience (case study) on the use of digital technologies for the development of the ability to invent stories for images in a collaborative way, in some nurseries (0-3 years) and in some kindergartens in La Spezia. We have involved in the experience: the sections of the older children of the nursery (3 years); the heterogeneous sections of kindergarten, with the aim of presenting different educational activities and technologies (PC, tablet, projector ...) - prepared by educators-teachers and researchers - in an immersive environment to enable children to enter into the image and interact with it. The collaborative activities have also predicted the use of $i$ Theatre, an interactive integrated system for the narrative creation of multimedia stories. During the activities, educators and researchers conducted free observations that aim to bring out possible elements of transferability of the experience and set the second stage of work (model of research-training).
\end{abstract}

Keywords: nursery, kindergarten, digital technologies, $i$-Theatre, narrative

\section{Introduction}

The organisation of nursery and kindergarten should be focussed on children, therefore, educators and teachers must structure a pedagogical and educational project that considers the needs of children (Restiglian, 2014). Educational decisions and actions must be negotiated to facilitate 'quality of learning' (Catarsi \& Fortunato, 2004).

In the nursery and kindergarten, children should be accepted in their 'historical and existential concreteness' (currently characterised by the presence of digital); the formative project should be focussed on this aspect. In this way, nursery and kindergarten are able to function according to the principles of 'educational continuity'.

Children need to learn in an environment where they can actively interact and build new meanings in a collaborative way (Lamberti, 2013). Activities must be structured to allow interaction and collaboration among children through an individual and original path that triggers a 'group dynamic' (Venza, 2007). This 'group dynamic' promotes growth and social relationships of each and all.

These reflections lead us to understand that the presentation of 'complex' experiences of learning with the use of digital cannot be random, but must be designed. The design of a 'technological and immersive environment' (Carletti \& Varani, 2007; Limone, 2012) rich and diverse, allows children to expand their experience. A technological environment like this urges the zone of proximal development (Vygotskij, 1974) of children by encouraging development and global learning. In this environment, children participate in the construction of knowledge. The experiences mediated by technologies (by mobile to simple computer), in different types of schools, are widespread, but not so much in the nursery and kindergarten. Teachers and educators do not determine clearly the advantages of the use of technological support in nurseries and kindergartens and the possible activities to do with children in these educational contexts. In the following contribution, we try to show how the use of technology in the nursery and kindergarten can help children to develop narrative skills through carefully designed activities.

\footnotetext{
${ }^{1}$ Valentina Pennazio wrote the Introduction and the Theoretical framework, Andrea Traverso wrote the Research design; the Trajectories of the digital experience and the Conclusion.
} 


\section{Theoretical framework}

\subsection{Technology environments in the nursery and kindergarten}

The introduction of mobile, of 2.0 applications (Anderson, 2007; Franklin \& Van Harmelen, 2007) and the latest 3.0 applications (Robin, 2011) promotes the creation of a learning environment that meets the needs of collaboration, of building shared meanings and new languages among children and young people of different ages.

Maragliano (1996) sustains that language learning is important, but is not universal. There are many other forms of learning that take place through intuitions, sounds or images. In this regard, the introduction of multimedia technology in nursery and kindergarten fosters multi-sensory experiences and multiple learning modalities, in game context, single, in small or large groups. Children are encouraged to expand their attention, develop new knowledge and a correct attitude of relationship with the audiovisual media. In this way, the passive hyperstimulation of children is deleted. For example, the use of a 'vibrating platform', experienced in some nurseries, allows children to experience reading a book by participating through the perception, the communication, the relation and the movement.

The new National Guidelines for the Curriculum (MIUR, 2012) of the kindergarten and the first cycle of education assign to technologies a strategic role in the dissemination of informations and communications. Children, already in kindergarten, can overcome the technological frontier using new media and the new tools available to them in a way functional to learning (Pennazio, Traverso, 2013). In particular, the goals that must be achieved at the end of kindergarten are connected to the creative dimensions (Invent, tell and dramatise stories; draw, paint, handle). These dimensions using the potential of technologies (images, sounds, colours) that allow children to explore their surroundings (the knowledge of the world). The technologies can influence the style of learning and knowledge acquisition (Mantovani, Ferri, 2008) and the methods of communication and relationship (in this case established by the ludic activity), improving the relations between the children. The technologies in the educational environment, with their plural nature, flexible and interchangeable, take on a ludic and animated nature (Cerri 2008, De Rossi 2008) becoming the cultural dimension.

\subsection{Technologies to invent and tell stories}

The technology must be thought, in relation to the educational contexts of nursery and kindergarten, not only in terms of procedure and technical tool, but also as a 'cultural dimension'. Bruner (1966), in this regard, highlights as the essence of learning is correlated with interactive tools that make possible the translation of the experience.

When they start to explore the world of symbols, children use many kinds of languages (iconic, graphic,...) and this is the premise for learning the alphabetic text (Ackermann, 1993). Technology fosters the use of these languages and this is why it's so important in services for early childhood.

The various technological supports (PC, mobile), extending the concept of written communication to forms capable of conveying a meaning (even without text), may allow children who are not yet able to read, to 'write' a multimedia history (Limone, 2010, 2011). The logics that involve the use of technology to the nursery are then attributable to: the constructionism (create knowledge together) (Nyikos \& Hashimoto, 1997); enhancement of images; to 'pasticciamento' with 'virtual pencils' (Chioccariello, 2000); to the mobilisation of energy and of motivation typical of game; the opportunity to animate their products and finally, the chance to see together what has been built.

The age of access to new digital technologies, also thanks to the touch screen, it is lowered: boys and girls will have a new way to play, discover and learn. All this supports new methods in which cognitive skills are refined, observation and listening time mutate, digital and analogue languages are intertwined by mixing the real to the virtual.

\section{3. i-Theatre: a tool to create multimedia stories}

i-Theatre is an interactive integrated narrative invention of multimedia stories dedicated to children. It recalls the 'suitcase-handcart' of 'wandering storytellers' and shows itself in its double aspect of tool and educational game. With this 'play tool', the narrative is linked to the technological dimension (De Blasio, Sorice, 2004; Staudenmaier, 1988). This system supports the child during the entire creative activity: predisposition of the characters and backgrounds (drawing on paper with the preferred technique); digitisation of the same and the creation and sharing of this animation. Children may develop and manipulate materials with 'slow times' that are necessary to promote the listening and sensitivity, which are indispensable for aesthetic perceptions - the base of sensory processes and creative thinking (Zavala , 2012). With i-Theatre, children create characters and environments in the physical world and then by digitising this to make a simple and intuitive 'animation making'.

The logic that governs ' $\mathrm{i}$-Theatre' is the 'Collaborative Learning Environment' (Cacciamani, 2008; Parmigiani, 2009): an environment that stimulates the sharing and the relation. In this way, the technology is not self-referential. The model of interaction that rules the system is not 'person - tool' not adapted to the needs of very young children, but 'person - person', within an environment where the technology is used in presence in a shared way, and considered one of the tools normally used in various activities (pencils, posters, paintings...). Children can: to draw the backgrounds and the characters of their own history, working alone or in groups; process a very simple storyboard, according to their 
ability; manipulate the shapes of the characters created by themselves (shift, rotation, zoom) using one fixed background; record the narration of the story, recounting with voice and moving the characters on screen. After the realisation of the movie, this can be screened on the wall to facilitate a shared vision among children. The story can be saved in a 'personal container' for subsequent visions.

Through this type of work, we promote the development of the expressive and reflexive dimension on the narrative process (narrative metacognition). Solicited is the collaboration of many children for the creation of a history of 'content complex' (with directors, actors, music, sound effects); solicited is the individual expression of a single starting from own personal inner world and the creative originality and the imagination by promoting the cognitive development of children. In fact, children are led to reflect on the narrative and recognise gradually in relation to their times and their cognitive styles, to: the different stages of the story, the main features, the rhythm, the colours through the opportunities offered by multimedia language.

\section{Research design}

\subsection{Research questions}

Our work can be plugged into an approach of 'case study' that, in education, wants to investigate the training systems in order to understand best practices and elements of transferability. We have chosen the 'case study' in order to collect information useful in the preparation of a broader experimentation in other kindergartens. This particular study focussed attention on a group of schools and educators (teachers) already trained in the use of technology in order to verify the effectiveness of their learning and level of expertise on the issues.

\subsection{Participants and context}

In the exploration and the first phase of field research, we decided to put our focus on nurseries and kindergartens in order to find possible constants or variables in the logic of 'educational continuity'. The decision to focus our attention on the field of early childhood education is linked to some pilot projects that our University has conducted in some nurseries and kindergartens in La Spezia, operated by the Cooperative Elios. In these early stages, we have involved four schools (two nurseries and two kindergartens).

\subsection{Methodology}

Starting from theoretical considerations above, we posed the following questions:

- can the use of 'digital' change the perspective and the way how children know the space?

- can the technologies support and amplify the languages of children?

- can the digital support new forms of narrative and story that are understandable and engaging for children of 0-3 years?

After the first phase of observation in which we found some elements of the digital and narrative context (cooperation, critical discussion, creativity), we set up 'immersive contexts' of play and exploration. We involved older children ( 2 years) of the nurseries and children of different ages (3-5 years) of the kindergartens.

We observed: the way in which children communicate, play, discover, 'structure / de-structure' the everyday context through the use of 'digital'; the way in which digital languages are intertwined with the traditional ones (both among children between the educators / teachers and children).

The 'immersive context' seemed to us the most suitable in consideration of the ages of the children attending the services 0-6 years. The use of PCs, tablets, webcams, projector allowed to structure the context called 'immersive'.

This context gives children the opportunity to: enter into the image and interact with it; become part of the playing actively between real and virtual; construct new narratives by collaborating with peers and adults.

We observed the children who interacted with virtual images and photographic and graphic representations (combining together reality and imagination) and focussed on narratives that have emerged from different contexts of digital experience.

Below, we present the scan of the activity: we have dedicated 2 weeks of work for each activity:

- First phase: reading and projecting virtual images. Initially, we proposed to read some books for early childhood (Guizzino, Lionni, 2006) that were the 'cultural and narrative frame' to the entire project. The images of the books, chosen by educators / teachers on the basis of their interactive potential, have been proposed with the light board projected on the wall (prevalence of ludic phase and visual stimulation). After activity of narration are followed activities of graphical reworking and manipulation activities to consolidate what has been seen and experienced by children to establish the narrative elements (mainly the storing phase and visual stimulation). It was finally proposed to use a 'platform of the constructivity' arranged by children with natural materials on the theme of the sea and the use of fish in plastic. The 'platform' can take on characteristics of background (Zanelli, 1986; Severi, Zanelli, 1990) on which to build the story, give it continuity, connect the experience of children with memory and the tangibility; 
- Second phase: creation of the 'immersive context'. The second step involved the introduction of digital media: PCs, tablets, projectors, interactive whiteboards, which have allowed the creation of an immersive context made of images before photographic and static, then in motion of seabed and scenarios (recovered in network) projected on the walls. Children are attracted by the images and sounds of the sea, they followed the light beams on their bodies trying to catch fish and objects that swam on the wall (prevalence of the exploratory phase and auditory-visual stimulation). This particular phase must absolutely provide the final moment of debriefing (Faithful, Frontani, Mengato, 2015) with children (conducted on the basis of real capacity of children - or habits - compared with a reflexive dimension of the game and learning);

- Third phase: the creation of a narrative plot. Later, the children were encouraged, in small group, to put in relation the objects of the platform with those of the projected images on the screen in order to find concordances and try to re-tell the story. Many children had been attracted to the projector and computer (for many of them, it was the first time they saw a projector) and showed a particular intuition to understand the source of images, their typology and what actions do to edit or interact with them. In the last phase of the activity, it was introduced in the 'immersive context' a webcam that allowed children to be active in reproducing images of their compositions (prevalence of 'creative-procedural' phase and visual stimulation);

- Fourth phase: the use of ' $i$-Theatre' to create multimedia stories. After this phase of exploration in immersive context, we tried to insert in the activity i-Theatre for the narrative invention of multimedia stories. The children drew the backgrounds and the characters of their story, working alone or in groups, and developed a storyboard very simple, depending on their capacity, with a clear efficacy in kindergartens (prevalence of artistic and creative phase and of 'physical-collaborative' stimulation). Interaction with 'the digital', on the touchscreen of the instrument allowed the children to manipulate the shapes of the characters that they have created, with a 'gestural vocabulary' very simple (move, rotate, zoom), by using a fixed background. After preparing the scene in the desired way, the children recorded the narration of the story, telling with their voice and moving the characters on the screen. After building a movie, this one was projected on the wall by facilitating shared vision among children. The story was then saved in the personal container - previously prepared - for subsequent visions.

\section{Trajectories of the digital experience}

This first phase of research, mainly observative and of gathering information (useful in defining good practice) has used 'design and didactic materials' of educators and teachers collected through a diary that was read and analysed by the working group. The decision of ethnographic order aims to valorise the experiential dimensions of our proposal and consequently learn more about the object on which rests the research and the pedagogical-didactic reflection.

Through this type of work, the development of the expressive and reflexive dimension was favoured on the narrative process (narrative metacognition).

Solicited was the collaboration of more children in the realisation of a history of complex content (with director, actors, music, sound effects), and also the individual expression of the child, dictated by the child's own personal inner world. The originality and imagination were valorised, by promoting cognitive development of children that reflected in the narrative (De Rossi, Petrucco, 2013) and the recognition of the different stages of the story, the main features, the rhythm, the colours. In particular, explored (and will subsequently be developed) were the following steps with the respective stimulations:

- ludic phase and visual stimulation;

- storing phase and visual stimulation;

- exploratory phase and visual-auditive stimulation;

- creative-procedural phase and visual and physical stimulation;

- creative phase and physical stimulation;

- creative phase and physical stimulation (social and collaborative).

The information collected during the study and in future experimentations is necessary to propose educational designs that take into account all aspects of learning. Through play and technology, the children can explore through the senses the development of their social dimension, the construction of identity promoted by the creativity and ability to propose solutions to problems.

\section{Conclusions}

In this first phase, the focus of the research group was concentrated on the interaction skills of children with the digital tools without assessing the full knowledge and control. The main idea was connected to 'make experience' and to live a gratifying and immersive situation. The observation, however, has highlighted some hooks that will be developed in the experimental phase of the research (implementation of the model) compared with: levels of attention and perception of the space and interpersonal relations; playfulness and emotional involvement (in relation to themselves, to other children and adults); success and gratification (Krug, 2005); satisfaction in terms of expectations, 


\section{The digital in the nursery and kindergarten: create immersive narratives through collaboration \\ Pennazio, Traverso}

commitment and strength (Read, MacFarlane \& Casey, 2001); collaboration (with the mediation of technology, enhancing the narrative dimensions and emotional sharing). The experience outlined here can also be a positive first practice that enhances the skills of teachers, encouraging them to specialise in the use of digital technologies and in their experimentations in education and teaching.

The final goal is to establish guidelines that combine the teaching experience with the ludic experience, the motor abilities with the relational abilities, by using the possibilities offered by advanced technologies. The possibilities offered by technologies (for school-family continuity; the formative dialogue with the families and the adults), will be outlined in the guidelines.

\section{References}

Ackermann, E. (1993). Système de notation chez l'enfant: leur piace dans la genèse de l'ecrit. In Les Entretiens Nathan - Parole, Ecrit, lmage. Paris: Nathan.

Anderson, P. (2007). What is Web 2.0? Ideas, technologies and implications for education. www.jisc.ac.uk/media/documents/techwatch/tsw0701b.pdf.

Bruner, J. (1966). Toward a theory of instruction. Cambridge: Harvard University Press.

Bruner, J. (1986). Actual minds, possible worlds. Cambridge: Harvard University Press.

Cacciamani, S. (2008). Imparare cooperando. Dal cooperative learning alle comunità di ricerca. Roma : Carocci.

Catarsi, E. \& Fortunati, A. (2004). Educare al nido. Metodi di lavoro nei servizi per l'infanzia. Roma: Carocci.

Chioccariello, A. (2000). Il computer nella scuola dell'infanzia. Modelli concettuali di riferimento e meccanismi di sostegno per i docenti. TD - Journal, Vol. 20, n. 2, pp. 36-43.

De Blasio \& E. Sorice, , M. (2004). Cantastorie mediali. Roma: Audino.

De RossiM. \& Petrucco, C. (2013). Le narrazioni digitali per l'educazione e la formazione. Roma: Carocci.

Fedeli, M., Frontani, L.\&Mengato, L. (2015). Experiential learning. Metodi, tecniche e strumenti per il de briefing. Milano: FrancoAngeli.

Franklin,T. \& Van Harmelen, M. (2007). Web 2.0 for content for learning and teaching in higher education. JISC www.jisc.ac.uk/media/documents/programmes/digitalrepositories/web2-content-learningand-teaching.pdf.

Krug, S. (2005). Don't Make Me Think. A Common Sense Approach to Web Usability, Berkeley: New Riders.

Lamberti, S. (2013). Apprendimento cooperativo nella scuola dell'infanzia. Percorsi e attività di educazione interculturale. Trento: Erickson.

Limone, P. (2012). Ambienti di apprendimento e progettazione didattica. Proposte per un sistema educativo transmediale. Roma: Carocci.

Limone, P. (2011). Design Partecipato ed innovazione degli ambienti di apprendimento: Sviluppo del sistema crossmediale "Coloredellastoria.it". In: I. Loiodice, Università, qualità della didattica e lifelong learning. Roma: Carocci, pp. 97-113.

Limone, P. (2010). Lo studio della cultura mediale infantile e il dibattito sulla mutata concezione dell'infanzia. In: S. Colazzo, Il Sapere Pedagogico. Roma: Armando, pp. 475-489.

Lionni, L. (2006). Guizzino. Milano: Babalibri.

Maragliano, R. (1996), Esseri multimediali. Immagini del bambino di fine millennio. Firenze:La Nuova Italia.

Mortari, L. (2004). Apprendere dall'esperienza. Il pensiero riflessivo della formazione. Roma: Carocci. 


\section{The digital in the nursery and kindergarten: create immersive narratives through collaboration}

Pennazio, Traverso

Nyikos, M. \& Hashimoto R. (1997). Constructivist Theory Applied to Collaborative Learning in Teacher Education. The Modern Language Journal, Vol. 81, n. 4, Special Issue: Interaction, Collaboration, and Cooperation: Learning Languages and Preparing Language Teachers, pp. 506-517.

Parmigiani, D. (2009). Tecnologie di gruppo. Collaborare in classe con i media. Trento: Erickson.

Pennazio,V. \& Traverso, A. (2013). Gioco e robotica per tutti nella scuola dell'infanzia. Bambini, Bergamo: Edizioni Junior.

Prenksy, M. (2001). Digital natives, digital immigrants. On the Horizon, 9 ,5, October, pp.1.

Read, J.C., Mac Farlane, S.J. \& Casey, C. (2001). Expectations and Endurability - Measuring Fun, conference proceeding at the Computers and Fun 4, York, England.

Restiglian, E. (2012). Progettare al nido. Teorie e pratiche educative. Roma: Carocci.

Rivoltella, P.C. (2011). I nativi digitali, gli "immigrati” o stranieri: quale dialogo sui valori e sulla fede è possibile tra le generazioni nell'era elettronica? Credere oggi, Padova: Edizioni Messaggero, pp. 64-75.

Robin, D. M. (2011). Web 3.0: Implications for Online Learning, TechTrends, Vol. 55, n. 1. Springer, January/February edition .

Severi, V. \& Zanelli, P. (1990). Educazione, complessità e autonomia dei bambini. Firenze: La Nuova Italia.

Staudenmaier, J. (1988). I cantastorie della tecnologia, Ritessere l'umana convivenza. Milano: Jaca Book.

Venza,G. (2007). Dinamiche di gruppo e tecniche di gruppo nel lavoro educativo e formativo. Milano: Franco Angeli.

Vygotsky, L.S. (1974). History of the Development of Higher Mental Functions. Trad. M.S. Veggetti (a cura di), Storia dello sviluppo delle funzioni psichiche superiori. Firenze: Giunti Barbera.

Zanelli, P. (1986). Uno “sfondo” per integrare. Bologna: Cappelli.

Zavalloni, G. (2012). La pedagogia della lumaca. Per una scuola lenta e nonviolenta. Bologna: EMI. 